\title{
Manganese (II) Chloride-Catalyzed Conjugated Addition of Amines to Electron Deficient Alkenes in Methanol-Water Medium
}

\author{
Anupam Roy, Dhiman Kundu, Shrishnu Kumar Kundu, Adinath Majee* and Alakananda Hajra*
}

Department of Chemistry, Visva-Bharati University, Santiniketan - 731235, India \begin{abstract}
methanol-water to produce the corresponding $\beta$-amino derivatives in excellent yields at room temperature.

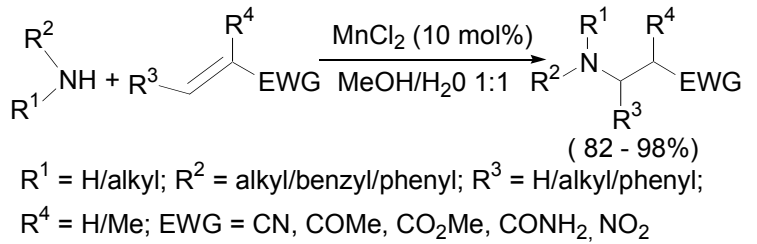

Abstract: A simple, general and efficient method has been developed for the conjugate addition of a variety of aliphatic and aromatic amines to electron deficient alkenes in the presence of a catalytic amount of manganese (II) chloride in

Keywords: Manganese (II) chloride, Michael addition, amines, $\alpha, \beta$-ethylenic compounds, methanol-water, chemoselectivity.

\section{INTRODUCTION}

The conjugate addition of amines to electron deficient alkenes is one of the most effective carbon-nitrogen bond forming reactions in synthetic organic chemistry [1]. It provides an easy route to produce $\beta$-amino derivatives, which are attractive for their use as synthetic intermediates of anticancer agents, antibiotics and other drugs [2]. Moreover, the $\beta$-amino ketone, nitrile, carboxylic ester and amide functionalities occur in many natural products [3]. The Mannich reaction is a classical method for the preparation of $\beta$-amino derivatives as for example the synthesis of $\beta$-amino acid derivatives reported by Ishitani and his co-workers [4] but this reaction has serious disadvantages, including low yields, long reaction times, and harsh reaction conditions. The conjugate addition of amines to electron deficient alkenes is, in contrast, atom economical and easy to operate. Usually these conjugate additions are carried out in the presence of a strong base or acid [5]. To avoid this harsh conditions, a number of milder procedures have been developed over the past few years using a variety of reagents such as $\mathrm{SnCl}_{4} / \mathrm{FeCl}_{3}$ [6], $\mathrm{InCl}_{3}$ [7], $\mathrm{CeCl}_{3} .7 \mathrm{H}_{2} \mathrm{O}$ $\mathrm{NaI}[8], \mathrm{Yb}(\mathrm{OTf})_{3}[9], \mathrm{Cu}(\mathrm{OTf})_{2}$ [10], CAN [11], $\mathrm{Bi}\left(\mathrm{NO}_{3}\right)_{3}$ [12], $\mathrm{Bi}(\mathrm{OTf})_{3}$ [13], $\mathrm{LiClO}_{4}$ [14], KF/alumina [15], $\mathrm{SmI}_{2}$ [16], $\mathrm{Cu}(\mathrm{acac})_{2} /$ ionic liquid [17], ionic liquid/quaternary ammonium salt in water [18], boric acid in water [19], $\beta$ cyclodextrin [20], $\mathrm{ZrOCl}_{2} .8 \mathrm{H}_{2} \mathrm{O}$ [21], borax [22], bromodimethylsulfonium bromide [23], $\left[\mathrm{HP}\left(\mathrm{HNCH}_{2} \mathrm{CH}_{2}\right)_{3} \mathrm{~N}\right] \mathrm{NO}_{3}$ [24], palladium [25] and nickel [26] etc. Although these methods are quite useful, many of these procedures require a large excess of reagents, long reaction time, drastic reaction conditions and toxic reagents as well as harmful solvents

*Address correspondence to these authors at the Department of Chemistry, Visva-Bharati University, Santiniketan - 731235, India; Tel: (0) 913463 264526; Fax: (0)91 3463 262728; E-mails: adinath.majee@visva-bharati.ac.in,

alakananda.hajra@visva-bharati.ac.in such as acetonitrile or 1,2-dichloroethane. Most of the reported methodologies are effective for either aromatic amines or aliphatic amines. Occasionally, these addition reactions can be performed in the absence of catalysts or water as the reaction medium, but in these cases the scope of the method is limited by solubility issues as well as by its lack of general applicability [27]. Therefore, development of a general, simple and convenient method, which can be applied to a number of substrates of different natures in a catalytic process under milder and environmentally friendly conditions, is highly desirable. With the increase of environmental consciousness in chemical research, reactions in water have attracted much attention in recent times [28]. In the present investigation, we would like to explore a simple and general procedure for the conjugate addition of a variety of amines to different Michael acceptors in the presence of a catalytic amount of manganese (II) chloride in methanol-water medium (Scheme 1).

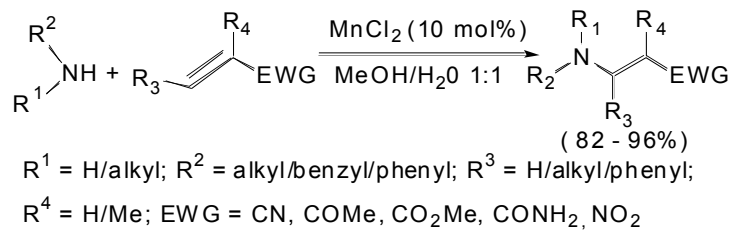

Scheme 1.

\section{RESULTS AND DISCUSSION}

Manganous chloride $\left(\mathrm{MnCl}_{2} .4 \mathrm{H}_{2} \mathrm{O}\right)$, a very inexpensive and easily available Lewis acid, is very easy to handle and relatively insensitive to air and moisture. In continuation of our work on the development of new synthetic methodologies, we found that manganous chloride could catalyze the addition of a variety of aliphatic and aromatic amines to electron deficient alkenes in methanol-water to produce the corresponding $\beta$-amino derivatives in excellent 
Table 1. $\mathrm{MnCl}_{2}$-Catalyzed Michael Addition of Amines to Conjugated Alkenes

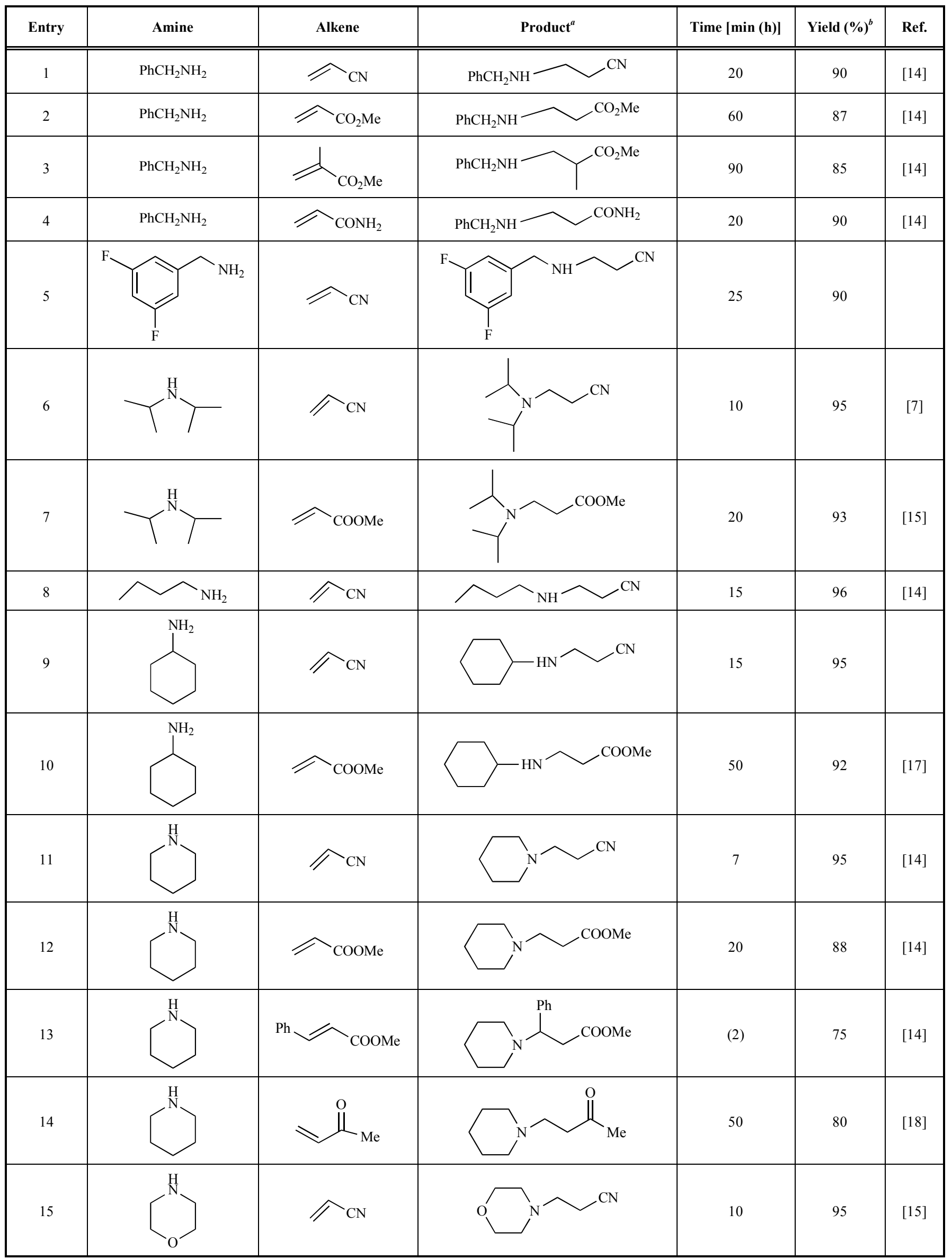




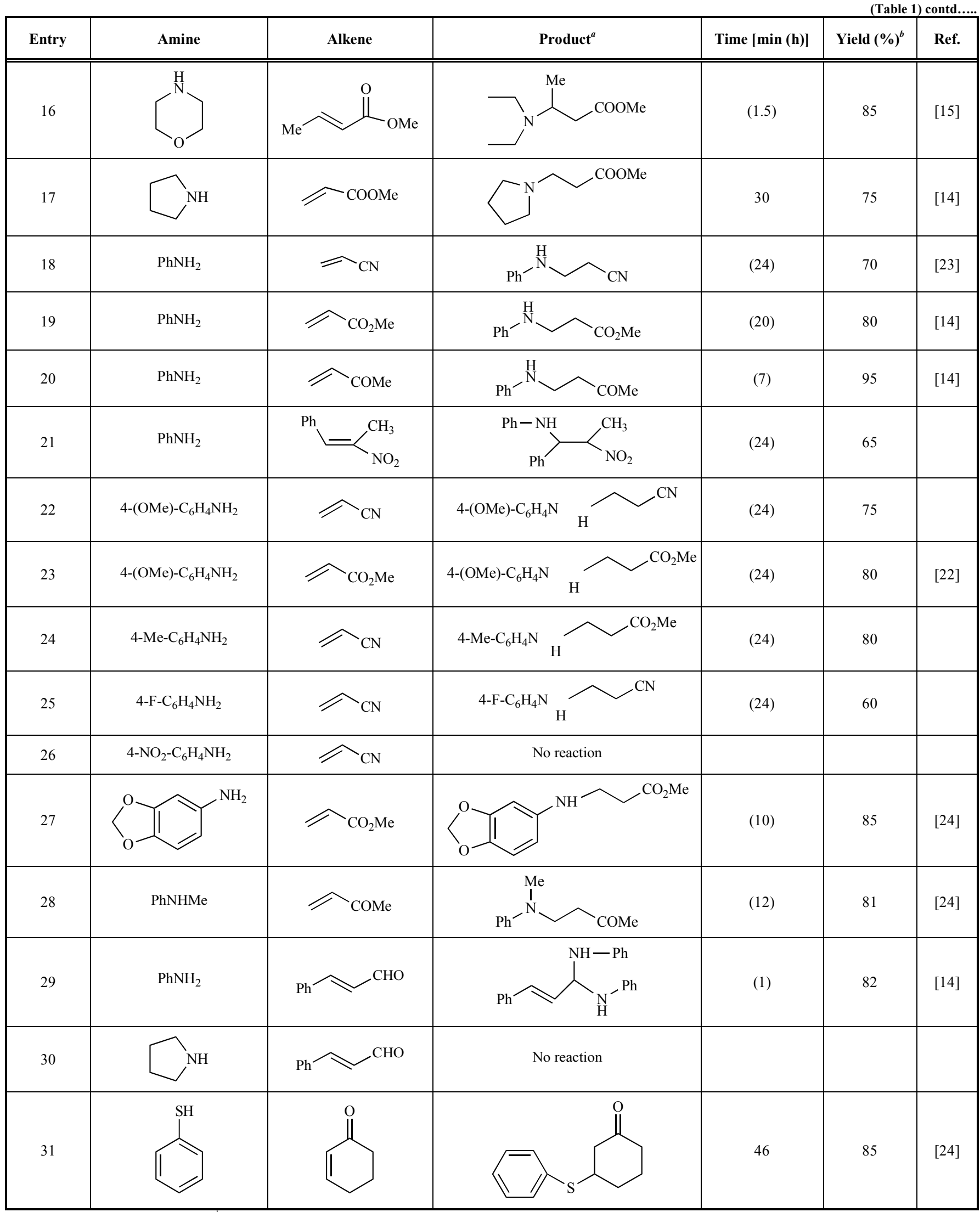

${ }^{a} \mathrm{MnCl}_{2}(10 \mathrm{~mol} \%) / \mathrm{MeOH}: \mathrm{H}_{2} \mathrm{O}(1: 1) .{ }^{b}$ Pure isolated yields. All the compounds were characterized by usual spectral and analytical methods.

yields at room temperature. The best result was achieved by carrying out the reaction with $10 \mathrm{~mol} \% \mathrm{MnCl}_{2}$ in $50: 50$ methanol-water medium. The reaction time is longer in absence of water. Reaction in water only is also slow and it 
may due to the solubility of different substrates. Using the optimized reaction conditions, several structurally varied amines were coupled with a wide range of $\alpha, \beta$-ethylenic compounds and the results are summarized in Table $\mathbf{1}$.

A variety of aliphatic amines was examined and the corresponding Michael adducts were isolated in excellent yields within a short time. The aliphatic primary amines such as benzylamine, substituted benzylamine, cyclohexylamine and butylamine were treated with different Michael acceptors and the corresponding monoadducts were isolated in good yields (entries 1-5 and 8-10). The reaction of an open chain bulky secondary amine like diisopropylamine proceeded very well (entries 6, 7). Cyclic secondary amines such as pyrrolidine, piperidine and morpholine underwent facile additions with acrylonitrile, acrylic esters and acrylamide (entries 11-17). Aromatic amines are less reactive than aliphatic amines and took longer reaction time. Both activated and weakly activated anilines were investigated. The reactions proceeded smoothly at room temperature and the products were obtained in excellent yields (entries 18-21). Several substituted anilines such as methyl, methoxy and flouro anilines underwent efficient additions with acrylonitrile and methyl acrylate giving only monoadducts in high yields under the present reaction conditions (entries 22-25). Sensitive functional groups in aniline such as 3,4-(methylenedioxy)aniline also reacted well to give the desired product in good yields keeping the methylenedioxy group unaffected (entry 27). However, anilines with strongly electron withdrawing groups such as 4-nitroaniline did not yield any product under the present reaction conditions (entry 26). $\mathrm{N}$-Methylaniline also reacted very well with methyl acrylate giving $81 \%$ yield (entry 28 ).

With regard to Michael acceptors, a wide range of structurally diverse electron deficient alkenes was used such as $\alpha, \beta$-unsaturated nitrile, carboxylic ester, ketone and amides. Acrylamide underwent Michael addition with benzylamine in very good yields (entry 4). The $\alpha, \beta$ unsaturated esters such as methyl acrylate, metyl methacrylate, methyl trans-cinnamate and methyl trans crotonate reacted with a wide variety of amines under the same reaction conditions to afford good yields of the corresponding adducts. Substituted nitro-styrene underwent Michael addition with aniline in very good yields (entry 21 ). $\alpha, \beta$-Unsaturated esters and nitriles are less reactive than the corresponding $\alpha, \beta$-unsaturated carbonyl compounds. Consequently, methyl vinyl ketone will take shorter reaction times in comparison with acrylonitrile and methyl acrylate. Table 1 corroborates this fact. In case of $\alpha, \beta$-unsaturated aldehydes, such as cinnamaldehyde, 1,2-addition is preferred and aminal was obtained exclusively when aniline was reacted with cinnamaldehyde. It was also found that cinnamaldehyde failed to react with pyrrolidine under similar reaction conditions. Thiophenol also reacted with $\alpha, \beta$-unsaturated alkenes smoothly in this method.

The difference in the reactivity of aromatic amines shows the chemoselectivity of the Michael addition of aliphatic amines in this method as shown in Scheme 2. Thus, when a mixture of aniline and benzylamine were exposed to acrylonitrile under the present reaction conditions, the benzylamine adduct was obtained as the sole product. In another experiment, a mixture of aniline and piperidine were added to methylacrylate. The mono Michael adduct of piperidine was obtained exclusively and clearly reflects the chemoselectivity of aliphatic amines versus aromatic amines. Another control experiment was performed with an equal mixture of aniline and piperidine with an excess of acrylonitrile under the same catalytic conditions. As expected, the former remained unaffected while the later furnished the addition product in high yields. This selectivity is due the smaller reactivity of aromatic amines in comparison to aliphatic amines. Here the role of manganese chloride is to activate the carbonyl group as other Lewis acid catalyst does followed by the nucleophilic addition of the amine. The reactivity of the aromatic and aliphatic amines is not influenced by the Lewis acid as the activation of carbonyl compounds is not to such extent. This selectivity could be useful to discriminate the two types of amines for synthetic applications.

In general, the reactions are very clean. Both aliphatic and aromatic amines give the products in equally fair yields. In particular, in the case of primary amines the method produces the corresponding $\beta$-amino derivatives without the problem of double-conjugate addition. It has also been observed that addition reactions occur only for aliphatic amines in water medium without catalyst [27].

\section{CONCLUSION}

In conclusion, this manganese (II) chloride-catalyzed procedure provides a highly efficient methodology for the synthesis of $\beta$-amino derivatives under milder conditions in methanol-water medium at room temperature. General applicability, operational simplicity, aqueous media, mild and environmentally friendly reaction conditions, high yields, and use of inexpensive and easily available reagents as catalyst are the advantages of the present procedure. We believe this Lewis acid-catalyzed aza-Michael reactions are of significant importance in both synthetic chemistry and industrial processes for the synthesis of $\beta$-amino derivatives.

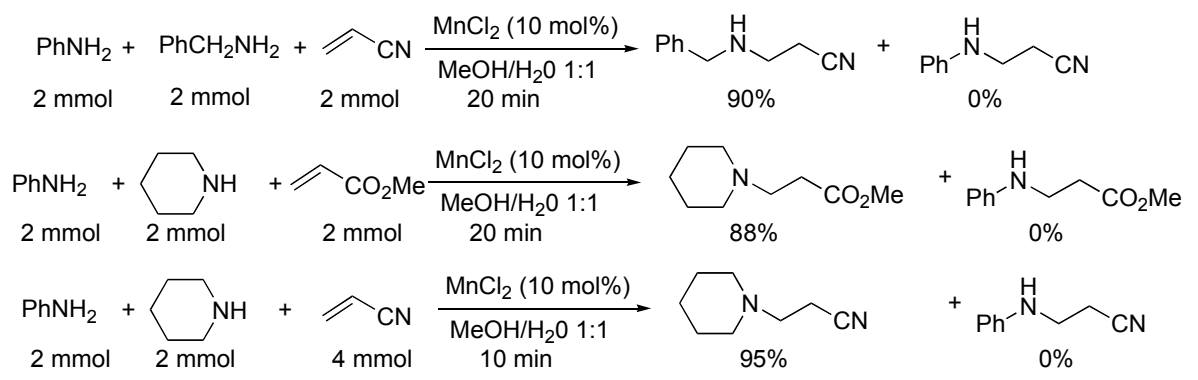

Scheme 2. Chemoselective conjugate addition of aliphatic amines in the presence of aromatic amines. 


\section{EXPERIMENTAL}

${ }^{1} \mathrm{H}$ NMR (300 MHz) and ${ }^{13} \mathrm{C}$ NMR (75 MHz) spectra were re recorded on a Bruker DPX 300 instrument in $\mathrm{CDCl}_{3}$ solutions. IR spectra were measured on a FT $8400 \mathrm{~S}$ Shimadzu spectrometer in $\mathrm{KBr}$ pellets. Elemental analyses were done by Perkin-Elmer autoanalyzer. Column chromatography was performed on silica gel (60-120 mesh, SRL, India). $\mathrm{MnCl}_{2} \cdot 4 \mathrm{H}_{2} \mathrm{O}$ was purchased from NICE Chemicals, India. Amines and alkenes are all commercial materials. All liquid reagents were distilled before use.

General procedure for the synthesis of $\beta$-amino derivatives. Representative procedure for Methyl 3piperidinyl-propionate (entry 12): A mixture of piperidine (170 mg, $2 \mathrm{mmol}, 198 \mu \mathrm{L})$ and methyl acrylate (172 mg, 2 mmol, $180 \mu \mathrm{L}$ ) was stirred in the presence of a catalytic amount of $\mathrm{MnCl}_{2}(40 \mathrm{mg}, 10 \mathrm{~mol} \%)$ in methanol-water (3 $\mathrm{mL}, 50: 50)$ at room temperature for $20 \mathrm{~min}$ as required for completion (TLC). After completion of the reaction, methanol was evaporated from the reaction mixture under reduced pressure. Ethyl acetate $(40 \mathrm{~mL})$ was added to the reaction mixture, and it was filtered through filter paper to remove manganous chloride. The extract was washed with water $(2 \times 10 \mathrm{~mL})$ and brine solution $(1 \times 10 \mathrm{~mL})$ and dried over anhydrous sodium sulphate. Evaporation of solvent followed by short column chromatography of the crude product over silica gel (hexane/ ethyl acetate 95:5) furnished the pure methyl 3-piperidinyl-propionate as a colorless oil (301 mg, 88\%), whose spectroscopic data (IR and NMR) are identical to those reported [27].

This procedure is followed for the synthesis of all the Michael adducts listed in Table 1. The known compounds have been identified by comparison of spectral data (IR and ${ }^{1}$ HNMR). The spectral and analytical data of the compounds which are not readily found are provided below.

3-(3,5-Difluoro-benzylamino)-propionitrile (entry 5, Table 1): Colorless liquid; IR 3482, 2925, 2267, 1735, 1612, $1418,1312 \mathrm{~cm}^{-1} ;{ }^{1} \mathrm{H}$ NMR $\delta 6.89-6.68(\mathrm{~m}, 2 \mathrm{H}), 6.68-6.21$ $(\mathrm{m}, 1 \mathrm{H}), 3.77(\mathrm{~s}, 2 \mathrm{H}), 2.88-2.85(\mathrm{~m}, 2 \mathrm{H}), 2.50-2.45(\mathrm{~m}$, $2 \mathrm{H})$, (N-H) not detected. ${ }^{13} \mathrm{C} \mathrm{NMR} \delta 164.5(2 \mathrm{C}), 140.4$, 118.2, 111.2(2), 100.1, 54.2, 44.3, 21.2. Anal. Cald for $\mathrm{C}_{10} \mathrm{H}_{10} \mathrm{~F}_{2} \mathrm{~N}_{2}$ : C, 61.22; H, 5.14; N, 14.28. Found: C, 61.02; $\mathrm{H}, 5.07 ; \mathrm{N}, 14.05$.

3-Cyclohexylamino-propionitrile (entry 9, Table 1): Colorless oil; IR 2928, 2246, 1722, 1666, 1558, $1455 \mathrm{~cm}^{-1}$; ${ }^{1} \mathrm{H}$ NMR $\delta 2.85(\mathrm{t}, J=5.1 \mathrm{~Hz}, 2 \mathrm{H}), 2.45(\mathrm{t}, J=5.1 \mathrm{~Hz}, 2 \mathrm{H})$, $2.43(\mathrm{~m}, 1 \mathrm{H}) 1.80-1.63(\mathrm{~m}, 5 \mathrm{H}), 1.25-1.16(\mathrm{~m}, 6 \mathrm{H}),{ }^{13} \mathrm{C}$ NMR $\delta$ 118.2, 51.2, 43.2, 34.1(2C), 27.1, 22.8(2C), 27. Anal. Cald for $\mathrm{C}_{9} \mathrm{H}_{16} \mathrm{~N}_{2}$ : C, 71.01; H, 10.59; N, 18.40. Found: C, 70.82; H, 10.35; N, 18.13.

(2-Nitro-1-phenyl-propyl)-phenylamine (entry 21, Table 1): Colorless oil; IR 3381, 2204, 1612, 1414, 1207 $\mathrm{cm}^{-1} ;{ }^{1} \mathrm{H}$ NMR $\delta 7.49-6.55(\mathrm{~m}, 10 \mathrm{H}), 4.84(\mathrm{~m}, 1 \mathrm{H}), 4.52$ $(\mathrm{m}, 1 \mathrm{H}), 1.47(\mathrm{~d}, J=7.1 \mathrm{~Hz}, 3 \mathrm{H}),(\mathrm{N}-\mathrm{H})$ not identified ; ${ }^{13} \mathrm{C}$ NMR $\delta 142.4,138.0,129.4,129.3$ (2C), 128.7 (2C), 127.1 (2C), 118.8, 114.1 (2C), 87.8, 61.7, 17.2. Anal. Cald for $\mathrm{C}_{15} \mathrm{H}_{16} \mathrm{~N}_{2} \mathrm{O}_{2}$ : C, 70.29; H, 6.29; N, 10.93. Found: C, 69.93; $\mathrm{H}, 6.03 ; \mathrm{N}, 9.81$.

3-(4-Methoxy-phenylamino)-propionitrile (entry 22, Table 1): Colorless liquid; IR 3377, 2244, 1842, 1617, 1514,
$1289 \mathrm{~cm}^{-1} ;{ }^{1} \mathrm{H}$ NMR $\delta 6.80(\mathrm{~d}, J=5.1 \mathrm{~Hz}, 2 \mathrm{H}) .6 .61(\mathrm{~d}, J=$ $5.1 \mathrm{~Hz}, 2 \mathrm{H}), 3.75(\mathrm{~s}, 3 \mathrm{H}), 3.47(\mathrm{t}, J=4.8 \mathrm{~Hz}, 2 \mathrm{H}), 2.61(\mathrm{t}, J$ $=4.8 \mathrm{~Hz}, 2 \mathrm{H}),(\mathrm{N}-\mathrm{H})$ not identified; ${ }^{13} \mathrm{C} \mathrm{NMR} \delta 152.9$, 140.3, 118.5, 115.1 (2C), 114.8 (2C), 55.8, 40.8, 18.2 Anal. Cald for $\mathrm{C}_{10} \mathrm{H}_{12} \mathrm{~N}_{2} \mathrm{O}: \mathrm{C}, 68.16 ; \mathrm{H}, 6.86 ; \mathrm{N}, 15.90$. Found: $\mathrm{C}$, 67.98; H, 6.53; N, 15.62.

3-(4-methyl-phenylamino)-propionitrile (entry 24, Table 1): Colorless liquid; IR 3559, 2253, 1615, 1522, 1404 $\mathrm{cm}^{-1}$; ${ }^{1} \mathrm{H}$ NMR $\delta 7.00(\mathrm{~d}, J=6.0 \mathrm{~Hz}, 2 \mathrm{H}), 6.53(\mathrm{~d}, J=6.0$ $\mathrm{Hz}, 2 \mathrm{H}), 3.47$ (d, $J=5.1 \mathrm{~Hz}, 2 \mathrm{H}), 2.60(\mathrm{~d}, J=5.1 \mathrm{~Hz}, 2 \mathrm{H})$, $2.24(\mathrm{~s}, 3 \mathrm{H})(\mathrm{N}-\mathrm{H})$ not identified; ${ }^{13} \mathrm{C}$ NMR $\delta 143.9,130.2$ (2C), 127.7, 118.5, 113.2 (2C), 40.0, 20.4, 18.0. Anal. Cald for $\mathrm{C}_{10} \mathrm{H}_{12} \mathrm{~N}_{2}$ : C, 74.97; H, 7.55; N, 17.48. Found: C, 74.63; $\mathrm{H}, 7.38 ; \mathrm{N}, 17.16$.

3-(4-Fluoro-phenylamino)-propionitrile (entry 25, Table 1): Colorless liquid; IR 3388, 2248, 1614, 1514, 1217 $\mathrm{cm}^{-1} ;{ }^{1} \mathrm{H}$ NMR $\delta 6.92-6.85(\mathrm{~m}, 2 \mathrm{H}), 6.56-6.51(\mathrm{~m}, 2 \mathrm{H})$, $3.43(\mathrm{t}, J=4.8 \mathrm{~Hz}, 2 \mathrm{H}), 2.58(\mathrm{t}, J=4.8 \mathrm{~Hz}, 2 \mathrm{H}),(\mathrm{N}-\mathrm{H})$ not detected. ${ }^{13} \mathrm{C}$ NMR $\delta 150.6,139.2,118.1,117.3(2 \mathrm{C}), 114.2$ (2C), 45.0, 19.3. Anal. Cald for $\mathrm{C}_{9} \mathrm{H}_{9} \mathrm{FN}_{2}$ : C, 65.84; H, 5.53; N, 17.06. Found: C, 65.61; H, 5.27; N, 16.84.

\section{ACKNOWLEDGEMENTS}

A. H. is pleased to acknowledge the financial support from DST (Grant No. SR/FTP/CS-107/2006). We are thankful to DST-FIST and UGC-SAP. D. K. thanks to CSIR for his fellowship. We also express our sincere thanks to Prof. B. C. Ranu, Department of Chemistry, Indian Association for the Cultivation of Science, for his advice and constant encouragement.

\section{REFERENCES}

[1] Permutter, P. Conjugated Addition Reactions in Organic Synthesis, Pergamon Press: Oxford, 1992.

[2] Banik, B. K.; Becker, F. F.; Banik, I. Synthesis of anticancer $\beta$ lactams: mechanism of action. Bioorg. Med. Chem., 2004, 12(10), 2523-28.

[3] Elango, S.; Yan, T.-H. A short synthesis of (+)-lycoricidine. Tetrahedron, 2002, 58(36), 7335-38.

[4] Ishitani, H.; Ueno, M.; Kobayashi, S. Enantioselective mannichtype reactions using a novel chiral zirconium catalyst for the synthesis of optically active $\beta$-amino acid derivatives. J. Am. Chem. Soc., 2000, 122(34), 8180-86.

[5] Jenner, G. Catalytic high pressure synthesis of hindered $\beta$ aminoesters. Tetrahedron Lett., 1995, 36(2), 233 -36.

[6] Wen, L.; Li, L.; Xia, C.-G. Transition-metal-based lewis acid catalysis of aza-type michael additions of amines to, $\alpha, \beta$ unsaturated electrophiles in water. Helv. Chim. Acta, 2004, 87(6), $1522-26$

[7] Loh, T. P.; Wei, L. L. Indium trichloride-catalyzed conjugate addition of amines to $\alpha, \beta$-ethylenic compounds in water. Synlett, 1998, (9), 975-76.

[8] Bartoli,G.; Bartolacci, M.; Giuliani, A.; Marcantoni, E.; Massimo, M.; Torregiani, E. Improved heteroatom nucleophilic addition to electron-poor alkenes promoted by $\mathrm{CeCl}_{3} \cdot 7 \mathrm{H}_{2} \mathrm{O} /$ naI system supported on alumina in solvent-free conditions. J. Org. Chem., 2005, 70(1), 169-74.

[9] Matsubara, S.; Yoshiyoka, M.; Utimoto, K. Lanthanoid triflate catalyzed conjugate addition of amines to $\alpha, \beta$-unsaturated esters. A facile route to optically active $\beta$ lactam. Chem. Lett., 1994, (5), 827-29.

[10] Xu, L.-W.; Li, J.-W.; Xia, C.-G.; Zhou, S.-L.; Hu, X.-X. Efficient copper-catalyzed chemo selective conjugate addition of aliphatic amines to $\alpha, \beta$-unsaturated compounds in water. Synlett, 2003, (15), 2425-27.

[11] Duan, Z.; Xuan, X.; Li, T.; Yang, C.; Wu, Y. Cerium(IV) ammonium nitrate (CAN) catalyzed aza-michael addition of 
amines to $\alpha, \beta$-unsaturated electrophiles. Tetrahedron Lett., 2006, 47(31), 5433-36.

[12] Srivastava, N.; Banik, B. K. Bismuth nitrate-catalyzed versatile Michael reactions. J. Org. Chem., 2003, 68(6), 2109-14.

[13] Varala, R.; Alam, M. M.; Adapa, S. R. Chemoselective michael type addition of aliphatic amines to $\alpha, \beta$-ethylenic compounds using bismuth triflate catalyst. Synlett, 2003, (5), 720-22.

[14] Azizi, N.; Saidi, M.R. $\mathrm{LiClO}_{4}$ Accelerated michael addition of amines to $\alpha, \beta$-unsaturated olefins under solvent-free conditions. Tetrahedron, 2004, 60(2), 383-87.

[15] Shaikh, N. S.; Deshpande, V.H.; Bedekar, A. V. Clay catalyzed chemoselective Michael type addition of aliphatic amines to $\alpha, \beta$ ethylenic compounds. Tetrahedron, 2001, 57(43), 9045-48.

[16] Reboule, I.; Gil, R.; Collin, J. Aza-michael reactions catalyzed by samarium Diiodide. Tetrahedron Lett., 2005, 46(45), 7761-64.

[17] Kantam, M. L.; Neeraja, V.; Kavita, B.; Neelima, B.; Chaudhuri, M. K.; Hussain, S. Cu(acac) $)_{2}$ Immobilized in liquids: A recoverable and reusable catalytic system for aza-Michael reactions. $A d v$. Synth. Catal., 2005, 347(6), 763-66.

[18] Karodia, N.; Liu, X.; Ludley, P.; Pletsas, D.; Stevenson, G. The ionic liquid ethyltri n-butylphosphonium tosylate as solvent for the acid-catalysed hetero-Michael reaction. Tetrahedron, 2006, 62(48), 11039-43.

[19] Chaudhuri, M. K.; Hussain, S.; Kantam, M. L.; Neelima, B. Boric acid: a novel and safe catalyst for aza-Michael reactions in water. Tetrahedron Lett. 2005, 46(48), 8329-31.

[20] Surendra, K.; Krishnaveni, N. S.; Sridhar, R.; Rao, K. R. $\beta$ Cyclodextrin promoted aza-Michael addition of amines to conjugated alkenes in water. Tetrahedron Lett., 2006, 47(13), 2125-27.

[21] Hashemi, M. M.; Eftekhari-Sis, B.; Abdollahifar, A.; Khalili, B. $\mathrm{ZrOCl}_{2} \cdot 8 \mathrm{H}_{2} \mathrm{O}$ on montmorillonite $\mathrm{K} 10$ accelerated conjugate addition of amines to $\alpha, \beta$-unsaturated alkenes under solvent-free conditions. Tetrahedron, 2006, 62(4), 672-77.

[22] Hussain, S.; Bharadwaj, S. K.; Chaudhuri, M. K. Kalita, H. Borax as an efficient metal-free catalyst for hetero-Michael reactions in an aqueous medium. Eur. J. Org. Chem., 2007, (2), 374-78.

[23] Khan, A. T.; Parvin, T.; Gazi, S.; Choudhury, L. H. Bromodimethylsulfonium bromide mediated Michael addition of amines to electron deficient alkenes. Tetrahedron Lett., 2007, 48(22), 3805-08.

[24] Fetterly, B. M.; Jana, N. K.; Verkade, J.G. [HP( $\left.\mathrm{HNCH}_{2} \mathrm{CH}_{2}\right)_{3} \mathrm{~N}$ ] $\mathrm{NO}_{3}$ : an efficient homogeneous and solid-supported promoter for aza and thia-Michael reactions and for Strecker reactions Tetrahedron, 2006, 62(2-3), 440-56.

[25] Hii, K. K. Development of palladium catalysts for asymmetric hydroamination Reactions. Pure. Appl. Chem., 2006, 78(2), 34149.

[26] Zhuang, W.; Hazell, R. G.; Jorgenson, K. A Catalytic enantioselective addition of aromatic amines to enones: synthesis of optically active $\beta$-amino acid derivatives. Chem. Commun. 2001, 1240-42.

[27] Ranu, B. C.; Banerjee, S. Significant rate acceleration of the azaMichael reaction in Water. Tetrahedron Lett., 2007, 48(1), 141-43.

[28] Kobayashi, S.; Sugiura, M.; Kitagawa, H.; Lam, W.W. Rare-earth metal triflates in organic synthesis. Chem. Rev., 2002, 102(6), 2227-302.

(C) Roy et al.; Licensee Bentham Open.

This is an open access article licensed under the terms of the Creative Commons Attribution Non-Commercial License (http://creativecommons.org/licenses/by-nc/ $3.0 /$ ) which permits unrestricted, non-commercial use, distribution and reproduction in any medium, provided the work is properly cited. 